\title{
DỨBin
}

Technological University Dublin ARROW@TU Dublin

2010-01-01

\section{Interactive Music Archive Access System}

\author{
Martin Gallagher \\ Technological University Dublin \\ Mikel Gainza \\ Technological University Dublin, Mikel.Gainza@tudublin.ie \\ Derry Fitzgerald \\ Technological University Dublin, derry.fitzgerald@tudublin.ie
}

See next page for additional authors

Follow this and additional works at: https://arrow.tudublin.ie/argcon

Part of the Electrical and Electronics Commons

\section{Recommended Citation}

Gallagher, M. et al. (2010) Interactive Music Archive Access System. IEEE International Conference on Multimedia \& Expo, ICME, Singapore, 2010.

This Conference Paper is brought to you for free and open access by the Audio Research Group at ARROW@TU Dublin. It has been accepted for inclusion in Conference papers by an authorized administrator of ARROW@TU Dublin. For more information, please contact arrow.admin@tudublin.ie, aisling.coyne@tudublin.ie, gerard.connolly@tudublin.ie. Funder: Enterprise Ireland Commercialisation Fund 
Authors

Martin Gallagher, Mikel Gainza, Derry Fitzgerald, Dan Barry, Matt Cranitch, and Eugene Coyle

This conference paper is available at ARROW@TU Dublin: https://arrow.tudublin.ie/argcon/59 


\title{
INTERACTIVE MUSIC ARCHIVE ACCESS SYSTEM
}

\author{
Martin Gallagher, Mikel Gainza, Derry Fitzgerald, Dan Barry, Matt Cranitch, Eugene Coyle
}

\author{
Audio Research Group \\ Dublin Institute of Technology \\ Kevin St., Dublin 2 Ireland \\ Email: martingallagher2@gmail.com, mikel.gainza@dit.ie, derry.fitzgerald@dit.ie \\ dan.barry@dit.ie,matt.cranitch@cit.ie, eugene.coyle@dit.ie
}

\begin{abstract}
The goal of the Interactive Music Archive Access System (IMAAS) project was to develop an interactive music archive access system which was capable of allowing an end-user to easily extract rhythmic, melodic and harmonic musical metadata descriptors from audio, and allow the user to interact with the archive contents in a manner not typically allowed in archive access systems. To this end, the IMAAS system incorporates a range of real-time interaction tools which allow the user to modify the retrieved audio in a number of ways including the ability to isolate individual instruments in stereo mixes, pitch and timescale modification, and beat-synchronous looping. This demo gives an overview of the capabilities of the IMAAS application.
\end{abstract}

Keywords - Real-time Audio Processing, Music Information Retrieval, Sound Source Separation, Tempo Estimation, Key and Time Signature Estimation, Music Transcription

\section{INTRODUCTION}

The Interactive Music Archive Access System (IMAAS) is designed as a simple, easy to use audio analysis and manipulation application. The playback of a wide range of audio formats, such as wav, mp3 and ogg are supported by the application, and the application was designed with cross-platform support in mind.

A standard transport bar incorporating playback tools and position display is incorporated. This can be set to display in time, on a sample basis or by bar and beat position. Also included is realtime selection of position on the audio waveform, and the ability to seamlessly select loops on the fly on the waveform. Further, the display adapts, automatically resizing depending on what tools are open in the application, and the user has the ability to select from a number of views of the audio waveform. The following sections give an overview of the IMAAS system and the technologies included in the system.

This work was funded by the Enterprise Ireland Commercialisation Fund

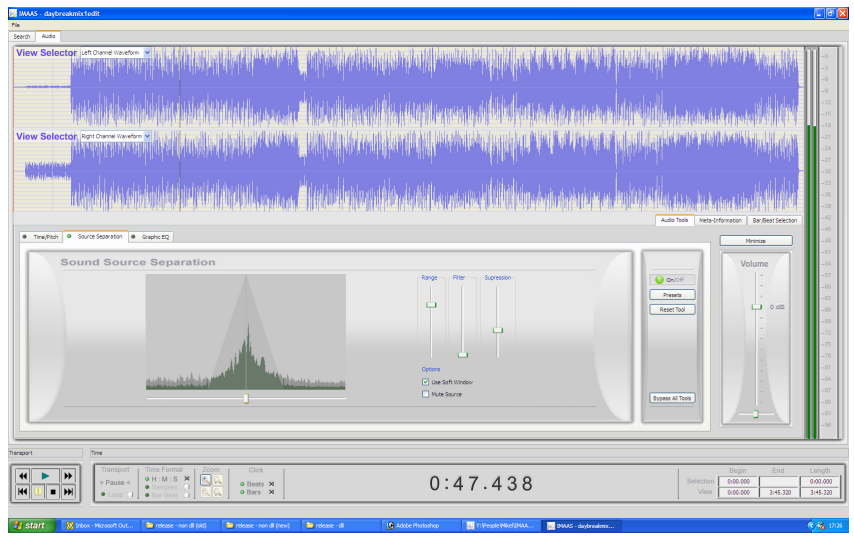

Fig. 1. IMAAS system - Sound Source Separation Tool

\section{REAL-TIME INTERACTION TOOLS}

The IMAAS system contains a number of real-time audio manipulation tools including sound source separation, independent pitch and time-scale modification and a graphic equaliser. All these tools can be used individually or chained together to allow simultaneous source separation and pitch change, for example.

The sound source separation tool, which can be seen in Figure 1, is an optimised version of the ADRess source separation algorith [1]. This algorithm is capable of separating sources which occupy unique positions in the stereo field by identifying frequency bins which have local minima in an "azimuthfrequency" plane at each time frame. These local minima are used to identify frequency bins belonging to a given pan position, which are then used to resynthesise the source at that position. Potential uses for this tool include isolating a given part so that a music student can learn the part with greater ease. The separation tool can also eliminate a given source to allow the user to play the part removed along with the original backing track.

Time and pitch-scale modification is achieved through an implementation of the techniques described in [2], which allows seamless independent changing of the pitch and tempo of the audio. Pitch shifting can be done in semitone intervals, with fine-tuning in cents, while time stretching can be set to a given 


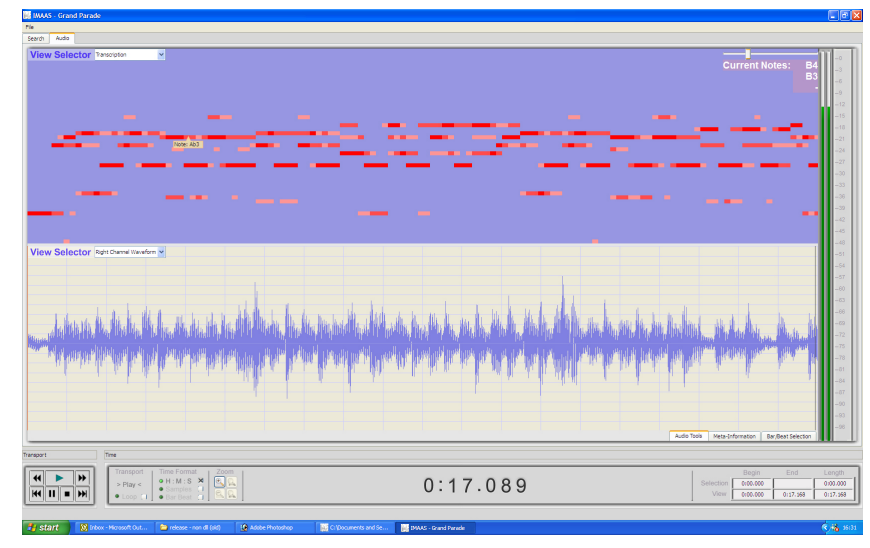

Fig. 2. IMAAS system- Transcription and waveform view

tempo once the tempo of the audio has been extracted by the MIR tools. This can be used to allow a student to change the key of a piece to an easier key to play, or to slow down the music while attempting to learn the piece.

Finally, the system incorporates a simple graphic equaliser to allow basic modification of the frequency profile of the piece of music.

\section{MUSIC INFORMATION RETRIEVAL TOOLS}

IMAAS allows the user to extract commonly used pieces of musical metadata such as meter,time signature, key signature, and tempo. Time signature estimation is based on an extension of the meter estimation algorithm described in [3] which uses beat similarity matrices to estimate the meter. Tempo estimation is done by an implementation of the hybrid multi-resolution approach described in [4]. Key signature estimation is based on an improved version of the algorithm presented in [5].

Polyphonic transcription of the audio is performed using an improved version of the algorithm described in [6], which is based on non-negative matrix factorisation techniques. This transcription is displayed in a piano-roll format. This can be seen in Figure 2. Once transcription has been performed the system also displays a list of the notes being played synchronised with the playback.

\section{SEGMENTATION}

When generating the musical metadata, IMAAS also generates a set of bar and beat markers. This is achieved by using the beat tracker described in [7]. An extension of this algorithm allows automatic detection of musical bar line positions. These bar and beat markers are used to drive a metronome which clicks in time with the music. This metronome also adapts to changes in tempo produced by the time-scale modification tool.

The availability of bar and beat markers also allows the user to select sections of audio using bar and beat positions. This allows easy selection and looping of musical phrases. This is also used to allow non-contiguous playback of the audio, where the user can select non-contiguous sections of the audio which will then play back seamlessly. This is useful to the user who wishes to study variations between repeated sections of the music, such as between two different verses.

\section{CONCLUSIONS}

An overview of the IMAAS application has been presented. This system incorporates a suite of real-time audio modification tools that are simple and easy to use. Also described were the MIR tools incorporated in the system, including rhythmic, harmonic and melodic descriptors such as key and time signature estimation and polyphonic transcription. The system is designed to be easy to use, hiding much of the algorithmic complexity of the audio modification and MIR tools behind a userfriendly interface.

\section{REFERENCES}

[1] D. Barry, B. Lawlor, and E. Coyle, "Real-time sound source separation using azimuth discrimination and resynthesis," in Proc. 117th Audio Engineering Society Convention, San Francisco, USA.

[2] D. Barry, D. Dorran, and E. Coyle, "Time and pitch scale modification: A real-time framework and tutorial," in Proc. Digital Audio Effects Conference 2008 (DAFX08), Espoo Finland.

[3] M. Gainza, "Automatic musical meter detection," in IEEE International Conference on Acoustics, Speech and Signal Processing (ICASSP09), Taipei, Taiwan.

[4] M. Gainza and E. Coyle, "Tempo detection using a hybrid multi-band approach," accepted for publication in IEEE Transactions on Audio, Speech and Language Processing, 2010.

[5] M. Hart, D. FitzGerald, and M. Cranitch, "Key signature estimation," in Proceedings of the Irish Signals and Systems Conference, Derry, Northern Ireland.

[6] D. FitzGerald, M. Cranitch, and E. Coyle, "Generalised prior subspace analysis for polyphonic pitch transcription," in Proceedings of the 8th International Conference on Digital Audio Effects (DAFX05), Madrid, Spain.

[7] M. Gainza, "On the use of a dynamic hybrid tempo detection model for beat tracking," in to be presented at IEEE Conference on Multimedia and Expo, 2010. 